\title{
Article \\ Evolution of the Structural State and Properties of 32CrB4 Steel during the Production of High-Strength Fasteners
}

\author{
Alexey Stepanov ${ }^{1}$, Anton Koldaev ${ }^{1}$, Nataliya Arutyunyan ${ }^{2, *}$ and Alexander Zaitsev ${ }^{1}$ \\ 1 Bardin Central Research Institute of Ferrous Metallurgy, 105005 Moscow, Russia; alxstp07@gmail.com (A.S.); \\ koldaevanton@gmail.com (A.K.); aizaitsev1@yandex.ru (A.Z.) \\ 2 Faculty of Chemistry, Lomonosov Moscow State University, 119991 Moscow, Russia \\ * Correspondence: naarutyunyan@gmail.com; Tel.: +7-495-939-1673
}

check for

updates

Citation: Stepanov, A.; Koldaev, A.;

Arutyunyan, N.; Zaitsev, A.

Evolution of the Structural State and

Properties of 32CrB4 Steel during the

Production of High-Strength

Fasteners. Metals 2022, 12, 366.

https://doi.org/10.3390/

met12020366

Academic Editors: Marcello Cabibbo

and Atef Saad Hamada

Received: 29 December 2021

Accepted: 18 February 2022

Published: 21 February 2022

Publisher's Note: MDPI stays neutral with regard to jurisdictional claims in published maps and institutional affiliations.

Copyright: () 2022 by the authors. Licensee MDPI, Basel, Switzerland. This article is an open access article distributed under the terms and conditions of the Creative Commons Attribution (CC BY) license (https:// creativecommons.org/licenses/by/ $4.0 /)$.

\begin{abstract}
For the production of high-strength fasteners, bar sections are used, which must withstand significant cold plastic deformation and, therefore, are subjected to a special heat treatment. In the present work, the dependences of the microstructure and mechanical properties of round bars with diameters of $17 \mathrm{~mm}$ and $21 \mathrm{~mm}$ made of 32CrB4 steel on the heat treatment modes are established. During the study, the methods of optical and scanning electron microscopy, mechanical tests, and hardness measurements were used. Dependences of the degree of spheroidization of the ferrite-pearlite structure and mechanical properties on the spheroidizing annealing mode have been established. It is shown that preliminary obtainment of a bainitic or martensitic structure of rolled products after hot-rolling of steel accelerates the process of pearlite spheroidization. Additional heat treatment, including austenitizing, quenching, and tempering, allows obtaining fasteners of various strength classes: 8.8, 9.8, and 10.9. However, with a guaranteed receipt of strength characteristics for all strength classes, including 12.9, the problem arises of achieving the required values of the relative elongation of steel.
\end{abstract}

Keywords: 32CrB4 steel; round bars; spheroidizing annealing; microstructure; globular cementite; mechanical properties; metallurgical quality

\section{Introduction}

High-strength fasteners are widely used in mechanical engineering, automotive, shipbuilding, and construction industries and other branches of technology. The traditional process for manufacturing them is heading and/or cold forging of steel round bars [1]. The bar sections used for this must have the specified mechanical properties and high-quality characteristics to ensure the capacity for cold upsetting [2,3]. To improve the mechanical properties of finished products, they are subjected to a final heat treatment, including quenching and tempering [4].

In real-world practice, for the production of high-strength bolts, medium-carbon and alloyed steels containing boron, manganese, and chromium are usually used, for example, 10B21, 20MnTiB, 32CrB4, and 34Cr4 [4]. These alloying elements increase strength and hardenability. A feature of boron addition is a significant increase in hardenability at very low concentrations (thousandths of a percent) $[5,6]$.

The typical microstructure of medium carbon steel round bars after hot-rolling is composed of ferrite and lamellar pearlite. Steel with lamellar pearlite morphology has inferior deformability and plasticity than cementite globular morphology [7]. Therefore, in order for the steel round bars to withstand significant plastic deformation during cold forging, it is preliminarily subjected to spheroidizing annealing. However, long spheroidizing annealing times (10 to $24 \mathrm{~h}$ ) are often required, which is energy-intensive [7,8]. Since at the present time energy saving is becoming the most important, the development of technologies for the production of bar sections is facing a similar challenge [9]. Therefore, many 
studies have been carried out to develop various methods to accelerate the spheroidization process: deformation of pearlite $[8,10,11]$, refinement of the original microstructure after rolling [12-16], cyclic heat treatment [17,18], subcritical annealing [7,19], and others. At the same time, the choice of the optimal modes for preliminary treatment and spheroidizing annealing is still carried out in relation to specific steel grades and production conditions. For boron steels, this information is limited, and for 32CrB4 steel, it is not available.

This work is devoted to the study of the evolution of the structural state and properties during the production of fasteners from boron-containing steels of the 32CrB4 grade. Particular attention is paid to the processes of obtaining a spheroidized pearlite structure of steel, which controls its manufacturability during cold forging, as well as the possibility of achieving mechanical properties of the resulting fasteners corresponding to various strength classes.

\section{Materials and Methods}

Hot-rolled round bars of industrial production with a diameter of 17 and $21 \mathrm{~mm}$ from $32 \mathrm{CrB} 4$ steel, the chemical composition of which is presented in Table 1, were investigated.

Table 1. Chemical composition of investigated 32CrB4 steel (wt $\%$ ).

\begin{tabular}{ccccccccccccccc}
\hline $\mathbf{C}$ & $\mathbf{S i}$ & $\mathbf{M n}$ & $\mathbf{S}$ & $\mathbf{P}$ & $\mathbf{C r}$ & $\mathbf{N i}$ & $\mathbf{C u}$ & $\mathbf{M o}$ & $\mathbf{A l}$ & $\mathbf{T i}$ & $\mathbf{V}$ & $\mathbf{B}$ & $\mathbf{N}$ & $\mathbf{C a}$ \\
\hline 0.32 & 0.21 & 0.65 & 0.003 & 0.010 & 0.91 & 0.03 & 0.04 & 0.002 & 0.024 & 0.040 & 0.005 & 0.0024 & 0.008 & 0.0026 \\
\hline
\end{tabular}

To ensure the correctness of the analysis of the effect of the spheroidizing annealing mode and microstructure on the ability to cold forge, the metallurgical quality of the obtained bar sections was preliminarily investigated. Analysis of the microstructure and the decarburized layer was carried out using a NEOPHOT-21 optical microscope (Carl Zeiss, Oberkochen, Germany). The surface of the microsections was etched with a Nital solution (a $4 \%$ solution of nitric acid in ethyl alcohol). Nonmetallic inclusions were identified by scanning electron microscopy (SEM) using a JSM-6610LV microscope (JEOL Ltd., Tokyo, Japan) with an INCA Energy Feature XT attachment for energy dispersive analysis. The total oxygen and nitrogen content in round-rolled products was determined by the method of reducing melting in an inert gas flow on a Leco TC-136 instrument (LECO Instruments $\mathrm{GmbH}$, St. Joseph, MI, USA).

To study the effect of the annealing mode on the intensity of the pearlite spheroidization process, various temperature and time parameters were selected (Table 2). The temperatures Ac1 and Ac3 for the investigated steel were found by thermodynamic calculation using our own software (Bardin TsNIIChermet, Moscow, Russia) [20]. Their values were 740 and $794{ }^{\circ} \mathrm{C}$, respectively.

Table 2. Parameters of the investigated modes of spheroidizing annealing.

\begin{tabular}{cccccc}
\hline Mode No. & $\begin{array}{c}\text { Temperature T1, } \\
{ }^{\circ} \mathbf{C}\end{array}$ & $\begin{array}{c}\text { Annealing } \\
\text { Duration at T1, h }\end{array}$ & $\begin{array}{c}\text { Duration of } \\
\text { Cooling to T2, h }\end{array}$ & $\begin{array}{c}\text { Temperature } \\
\text { T2, }{ }^{\circ} \mathbf{C}\end{array}$ & $\begin{array}{c}\text { Annealing } \\
\text { Duration at T2, h }\end{array}$ \\
\hline 1 & 700 & 4 & - & - & - \\
2 & 730 & 4 & - & - & - \\
3 & 760 & 4 & - & 690 & 4 \\
4 & 760 & - & 4 & 690 & 4.1 \\
\hline
\end{tabular}

From the data in Table 2, it can be seen that the temperatures of spheroidizing annealing are below Ac1 by $40{ }^{\circ} \mathrm{C}$ (mode No. 1), below Ac1 by $10{ }^{\circ} \mathrm{C}$ (mode No. 2), and higher than Ac1 by $20^{\circ} \mathrm{C}$ (mode No. 3). In addition, a mode with continuous slow cooling from the two-phase region $\left(760^{\circ} \mathrm{C}\right.$ ) to a temperature below Ac1 by $50{ }^{\circ} \mathrm{C}$ (mode No. 4) was investigated as well as a method of short-term heating to a temperature above Ac1 
by $20^{\circ} \mathrm{C}$ with accelerated cooling to $690^{\circ} \mathrm{C}$ and subsequent isothermal exposure (mode No. 5). According to the modes presented in Table 2, samples of round bars with a diameter of 17 and $21 \mathrm{~mm}$, lengths of 10 and $120 \mathrm{~mm}$ in the initial hot-rolled state, were annealed in a tubular electric resistance furnace equipped with a thermostat that allows to set and measure the temperature with an accuracy of $\pm 1-2{ }^{\circ} \mathrm{C}$ for any selected mode. The efficiency of different modes of spheroidizing annealing was determined by studying the structure of annealed samples of round bars using the method of visual determination of the ratio of globular and lamellar pearlite.

In order to study the effect of the structural state of round bars after hot-rolling on the efficiency of the pearlite spheroidization process, samples of hot bar sections with a diameter of 17 and $21 \mathrm{~mm}$ and a length of 10 and $120 \mathrm{~mm}$ were preliminarily subjected to austenitization at $860^{\circ} \mathrm{C}$ for $30 \mathrm{~min}$, followed by quenching in oil, cooling on air, as well as with a furnace. Microstructure analysis was performed using a NEOPHOT-21 optical microscope (Carl Zeiss, Oberkochen, Germany) and a JSM-6610LV scanning electron microscope (JEOL Ltd., Tokyo, Japan). The assessment of the quantitative ratio of structural components was carried out after the analysis of 10 images of samples.

To assess the possibility of manufacturing high-strength fasteners of various strength classes made of 32CrB4 steel, a study of the effect of the processes of quenching and tempering round-rolled samples at various temperatures on the mechanical properties was carried out. The research methodology was as follows. Samples of round bars with a diameter of 17 and $21 \mathrm{~mm}$, with a length of $120 \mathrm{~mm}$, were subjected to austenitization in a tube furnace at $860^{\circ} \mathrm{C}$ for $1 \mathrm{~h}$, followed by quenching in oil. After cooling to room temperature, the samples were tempered in the same furnace at temperatures from 400 to $550{ }^{\circ} \mathrm{C}$.

Mechanical properties were determined using a tensile testing machine HECKERT FP-100/1 (VEB MWK Fritz Heckert, Chemnitz (Karl-Marx-Stadt), Germany (GDR): tensile strength $\left(\sigma_{B}\right)$, yield strength $\left(\sigma_{0.2}\right)$, relative elongation $(\delta)$, relative reduction $(\Psi)$.

To assess the hardenability of the steel under study after quenching, the microhardness was measured using Struers Duramin-20 tester (Struers ApS, Ballerup, Denmar) on microsections made from the middle part of hardened samples, in diameter with a step of $0.5 \mathrm{~mm}$. If it was necessary to analyze hardness values in other units of measure, hardness conversion tables according to DIN 50150 were used.

To assess the average value of hardness, the method for determining the Rockwell hardness by means TK hardness tester (Krasnolit plant, Krasnodar, USSR) with a load of $150 \mathrm{kgf}$ was used.

\section{Results}

\subsection{Mechanical Properties and Microstructure of Hot-Rolled Round Bars}

The results of determining the mechanical properties of the original round bars are presented in Table 3.

Table 3. Mechanical properties of the original round bars.

\begin{tabular}{cccccc}
\hline \multirow{2}{*}{ Batch No. } & \multirow{2}{*}{ Diameter, $\mathbf{m m}$} & \multicolumn{4}{c}{ Mechanical Properties } \\
\cline { 3 - 5 } & & $\boldsymbol{\sigma}_{\mathbf{0 . 2}}, \mathbf{M P a}$ & $\boldsymbol{\sigma}_{\mathbf{B}}, \mathbf{M P a}$ & $\boldsymbol{\delta}, \boldsymbol{\%}$ & $\mathbf{\Psi}, \mathbf{\%}$ \\
\hline 1 & 17 & 355 & 610 & 23 & 59 \\
2 & 21 & 370 & 625 & 23 & 58 \\
\hline
\end{tabular}

From the data in Table 3, it follows that two batches of round bars have similar values of mechanical properties, which indicates their independence from the diameter.

The results of the study of the microstructure showed that the samples of round bars have a ferrite-pearlite microstructure with a 50/50 ratio of pearlite and ferrite. According to the estimate, the size of ferrite grains and pearlite colonies is about 10 microns. A typical view of the microstructure of round bars with a diameter of $17 \mathrm{~mm}$ is shown in Figure 1. 


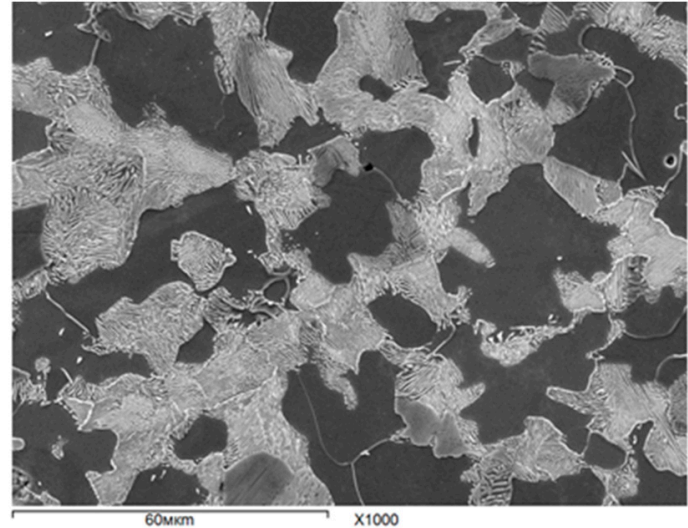

(a)

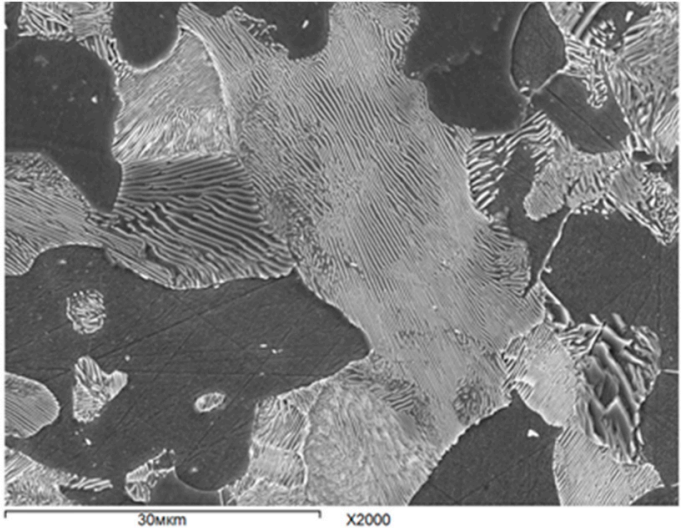

(b)

Figure 1. View of the microstructure of round bars with a diameter of $17 \mathrm{~mm}$ (SEM) at various magnifications: (a) $\times 1000$; (b) $\times 2000$.

\subsection{Metallurgical Quality Study}

The results of the study by the methods of light microscopy showed that the hot-rolled bars have partial decarburization of the surface with a depth of $0.3-0.6 \%$ of the diameter of the bars (Figure 2).

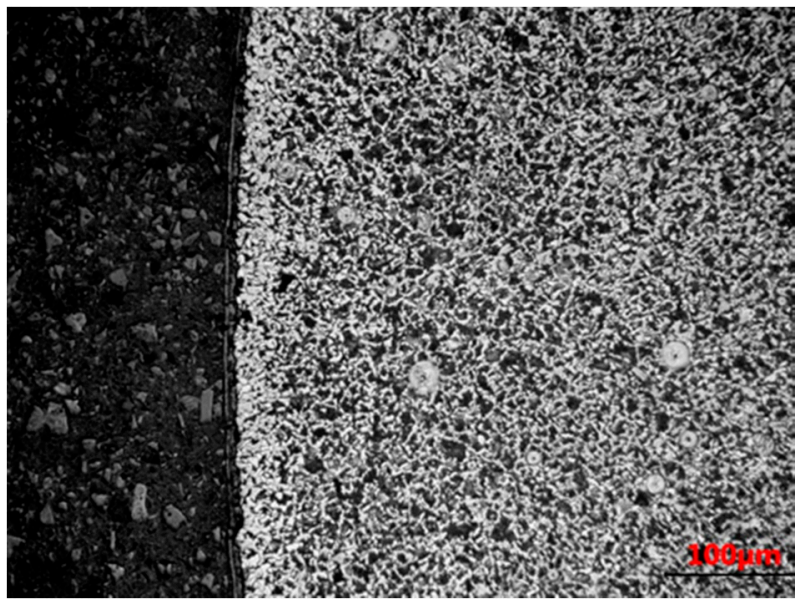

(a)

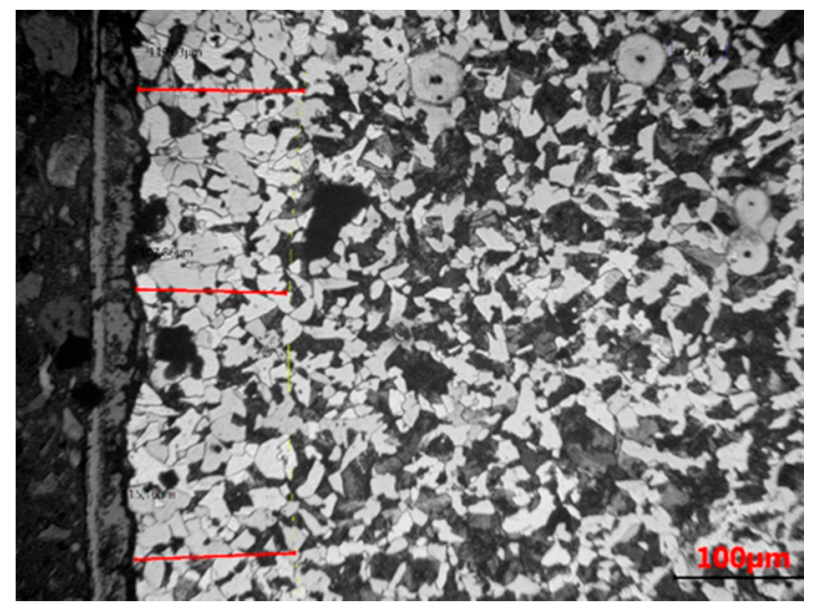

(b)

Figure 2. View of areas with partial decarburization of the surface of round bars with a diameter of $21 \mathrm{~mm}$ at various magnifications: $(\mathbf{a}) \times 50 ;(\mathbf{b}) \times 200$.

From the data in Figure 2, it follows that the specimens contain rather short (less than $10 \%$ of the circumference) single sections of local partial decarburization, which, most likely, are formed during hot-rolling.

To assess the metallurgical quality of the steel, the characteristics of the nonmetallic inclusions present were studied by SEM and local X-ray spectral analysis, as well as the determination of the total oxygen and nitrogen content in the axial and near-surface zones of the rolled product. The results are shown in Table 4 and Figure 3.

Table 4. The total oxygen and nitrogen content in round bars with a diameter of $21 \mathrm{~mm}$.

\begin{tabular}{ccc}
\hline Study Area & Total Oxygen Content, ppm & Total Nitrogen Content, ppm \\
\hline Axial zone & 25 & 105 \\
Near-surface zone & 20 & 110 \\
\hline
\end{tabular}



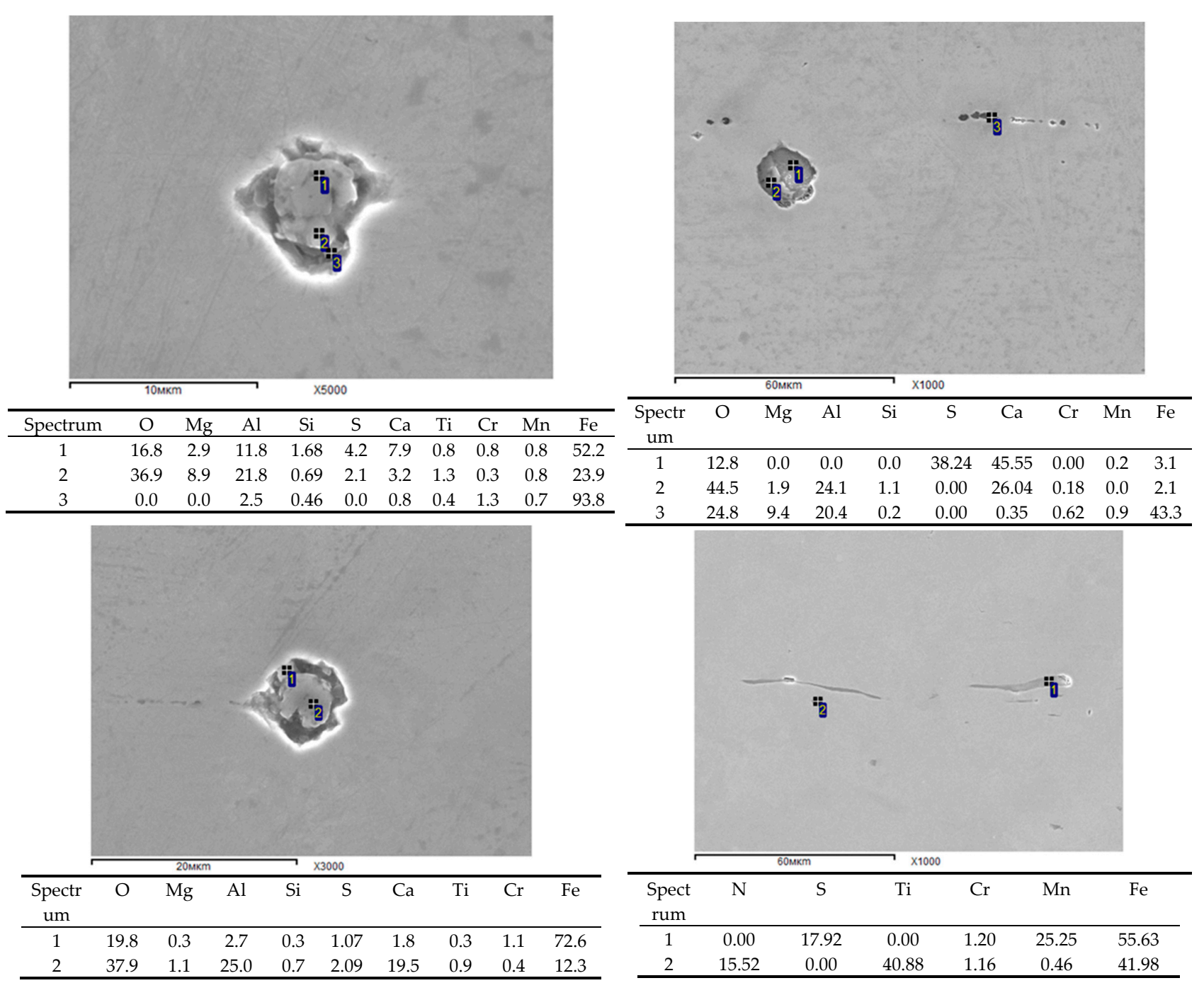

Figure 3. Typical view and composition of nonmetallic inclusions in round bars. The spectra correspond to the points indicated on the images.

From the data in Table 4 and Figure 3, it can be seen that the main types of nonmetallic inclusions are oxide inclusions based on calcium aluminates, aluminum-magnesium spinel, and titanium nitride. Despite the relatively low values of the total oxygen content (20-25 ppm), it can be seen that the metal contains a fairly large number of oxide inclusions, including large ones up to 20-30 microns in size. This indicates that a significant contribution to the considered value is made by oxygen, which is part of the chemical composition of nonmetallic inclusions, and there is a possibility of increasing the steel purity from nonmetallic inclusions due to their assimilation by the cover slag. The data in Figure 3 indicate that large oxide inclusions during rolling form lines with a length of up to 100-200 microns. Additionally, rolled manganese sulfide inclusions with a length of 40-60 microns were detected. It is important to note that the bars contain accumulations of large titanium nitride inclusions of 5-10 microns. Their content in the axial zone of the bars is much higher. From the data in Table 4, it follows that the presence of such inclusions is due to the high nitrogen content in the steel. It is obvious that the presence of the described types of nonmetallic inclusions can adversely affect the service characteristics of high-strength fasteners, including fatigue strength, corrosion resistance, and operational reliability. Nevertheless, tests of round bars after spheroidizing annealing for cold upsetting at $1 / 3$ of the original height of the cylindrical specimen showed a positive result. 
Consequently, the presence of nonmetallic inclusions in the investigated rolled products does not lead to a significant decrease in its quality characteristics.

\subsection{Study of the Influence of the Spheroidizing Annealing Mode on the Microstructure and} Mechanical Properties

Figure 4 and Table 5 show the type of microstructure of the investigated round bars and its characteristics after spheroidizing annealing was carried out according to various modes (Table 2).

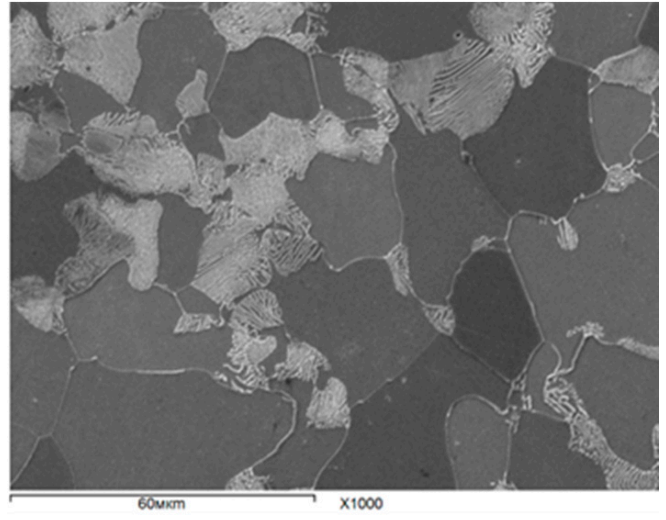

(a)

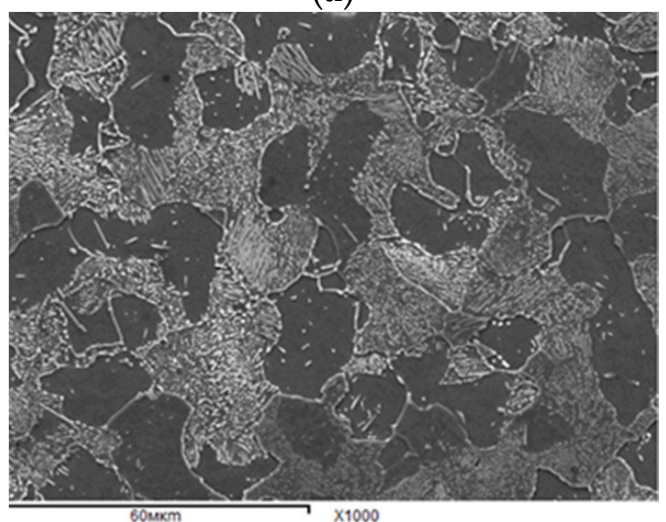

(c)

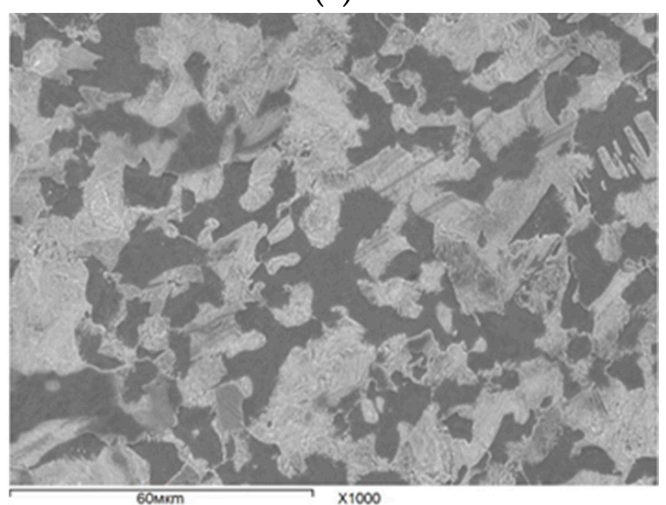

(e)

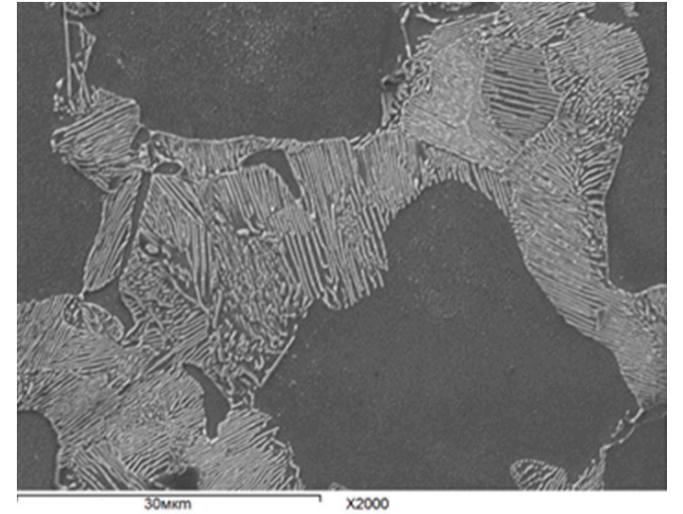

(b)

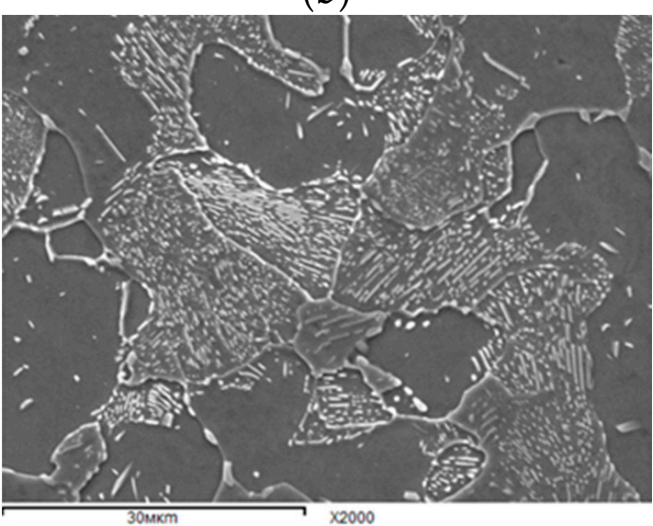

(d)

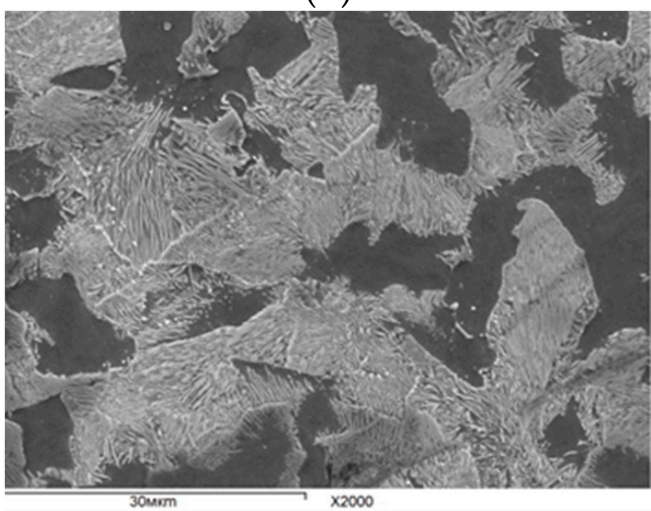

(f)

Figure 4. Cont. 


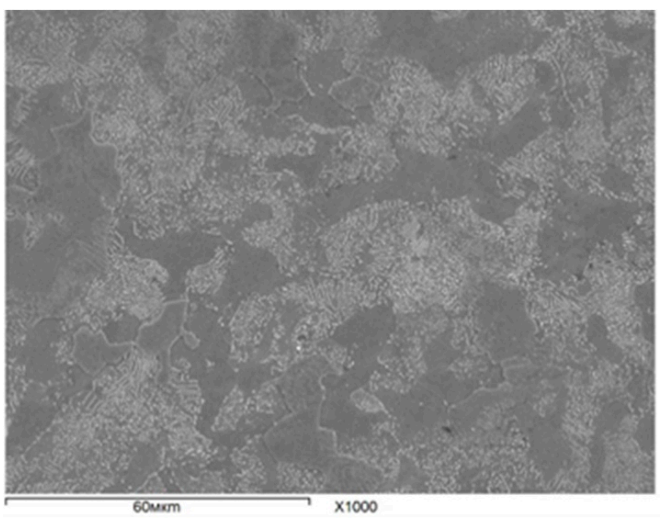

$(\mathrm{g})$

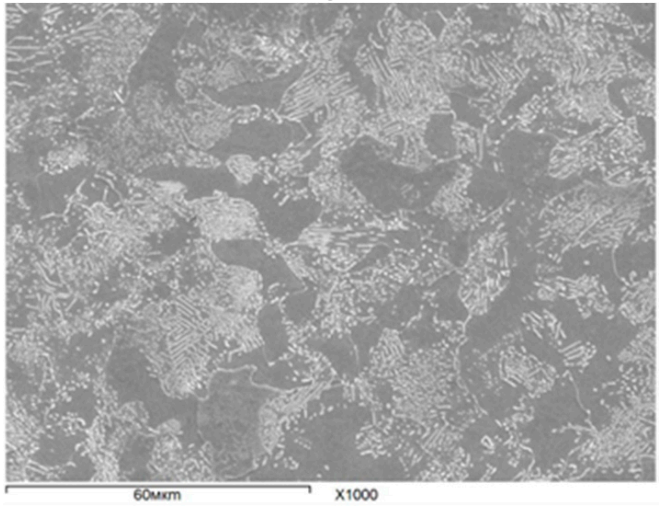

(i)

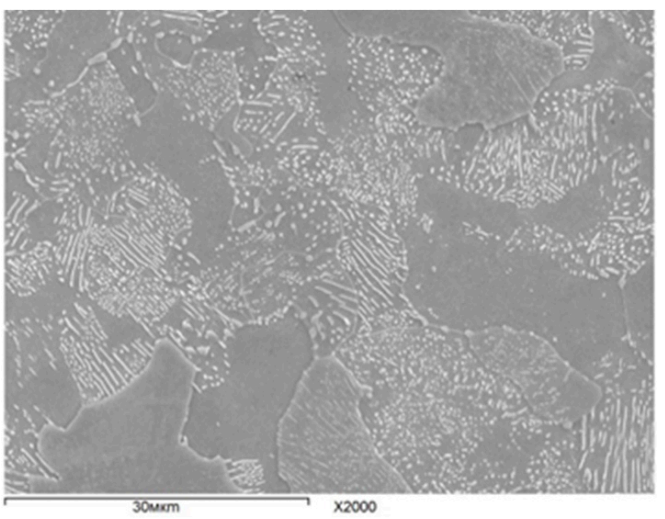

(h)

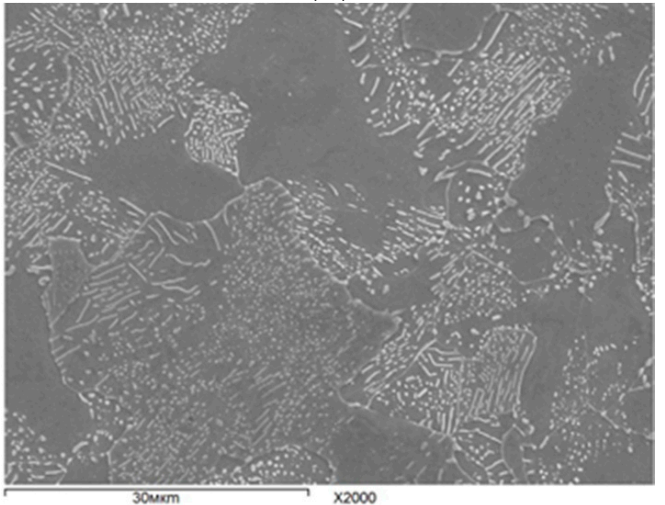

(j)

Figure 4. View of the microstructure of samples of round bars of various diameters after spheroidizing annealing according to various modes: (a,b) Mode No. 1, $17 \mathrm{~mm}$; (c,d) Mode No. 2, $17 \mathrm{~mm}$; (e,f) Mode No. 3, 17 mm; (g,h) Mode No. 4, $21 \mathrm{~mm} ;(\mathbf{i}, \mathbf{j})$ Mode No. 5, $17 \mathrm{~mm}$.

Table 5. Characteristics of the microstructure of round bars after spheroidizing annealing according to various modes.

\begin{tabular}{cccc}
\hline Mode No. & Diameter, mm & $\begin{array}{c}\text { The Ratio of Globular and } \\
\text { Lamellar Pearlite, } \%\end{array}$ & $\begin{array}{c}\text { The Ratio of Perlite and } \\
\text { Ferrite, } \%\end{array}$ \\
\hline \multirow{2}{*}{1} & 17 & $5 / 95$ & $35 / 65$ \\
2 & 21 & $5 / 95$ & $35 / 65$ \\
\hline \multirow{2}{*}{2} & 17 & $35 / 65$ & $50 / 50$ \\
& 21 & $35 / 65$ & $50 / 50$ \\
\hline \multirow{2}{*}{3} & 17 & $5 / 95$ & $50 / 50$ \\
& 21 & $5 / 95$ & $50 / 50$ \\
\hline \multirow{2}{*}{5} & 17 & $80 / 20$ & $75 / 25$ \\
& 21 & $80 / 20$ & $75 / 25$ \\
\hline
\end{tabular}

From the data in Table 5 and Figure 4, it can be seen that annealing modes No. 1 and No. 3 are the least effective. After spheroidizing annealing according to these modes, the fraction of globular pearlite does not exceed 5\%. It can be seen that holding at a temperature below Ac1 by $40{ }^{\circ} \mathrm{C}$ practically does not lead to an increase in the fraction of globular pearlite. This may indicate that the process of cementite globulization had a low thermodynamic stimulus and transformation rate. Despite the close results obtained after holding at a temperature of $760^{\circ} \mathrm{C}$ (mode No. 3), it can be assumed that in this case, cementite was partially dissolved in the formed austenite. Due to the rapid cooling from 
the two-phase region, processes occurred, leading to the formation of lamellar pearlite. Holding the metal at a temperature below $\mathrm{Ac} 1$ by $10{ }^{\circ} \mathrm{C}$ (mode No. 2) made it possible to achieve a degree of pearlite globulation of $35 \%$. Since the holding temperature practically corresponded to the Ac1 temperature, a further increase in the fraction of globular pearlite without a transition to the two-phase region is only possible with an increase in the duration of annealing or a change in the structural state of the metal before annealing. The most interesting results were obtained in annealing modes in which heating to the temperature of the corresponding two-phase region was performed, followed by slow and accelerated cooling to a temperature below Ac1 by $50{ }^{\circ} \mathrm{C}$. With an identical duration of annealing $(4 \mathrm{~h})$, it was possible to increase the proportion of spheroidized pearlite from $5-35 \%$ to $65-80 \%$.

The mechanical properties of cylindrical samples of round bars with a diameter of $17 \mathrm{~mm}$ and a length of $120 \mathrm{~mm}$ after spheroidizing annealing according to various modes were determined. The results are shown in Table 6.

Table 6. Mechanical properties of samples of the investigated round bars with a diameter of $17 \mathrm{~mm}$ after spheroidizing annealing according to various modes.

\begin{tabular}{|c|c|c|c|c|}
\hline \multirow{2}{*}{ Batch No. } & \multicolumn{4}{|c|}{ Mechanical Properties } \\
\hline & $\sigma_{0.2}, \mathrm{MPa}$ & $\sigma_{\mathrm{B}}, \mathrm{MPa}$ & $\delta, \%$ & $\Psi, \%$ \\
\hline 1 & 320 & 580 & 24.5 & 63 \\
\hline 1 & 325 & 580 & 22.5 & 61 \\
\hline 2 & 300 & 540 & 22.5 & 63 \\
\hline 2 & 310 & 550 & 22.5 & 64 \\
\hline 3 & 400 & 670 & 22.5 & 70 \\
\hline 3 & 410 & 680 & 19.5 & 75 \\
\hline 4 & 310 & 530 & 27.0 & 72 \\
\hline 4 & 305 & 530 & 24.0 & 69 \\
\hline 5 & 340 & 580 & 21.0 & 64 \\
\hline 5 & 340 & 580 & 21.5 & 66 \\
\hline
\end{tabular}

From the data in Table 5 and Figure 4, it follows that the most effective modes of spheroidizing annealing of the investigated round bars are No. 2, 4, and 5 . It can be seen that under these modes, the maximum values of the ratio of globular and lamellar pearlite were achieved. However, from the data in Table 6, it follows that the mechanical properties of bar samples, which meet the requirements of EN10263-4 for steel of 32CrB4 grade $\left(\sigma_{\mathrm{B}}=550 \mathrm{MPa}, \Psi=62 \%\right)$, are only achieved when using spheroidizing annealing modes No. 2 and No. 4.

Table 7 summarizes the characteristics of the microstructure of bars subjected to preliminary heat treatment before spheroidizing annealing. A typical view of the microstructure is shown in Figure 5.

Table 7. Characteristics of the microstructure of round bars after preliminary heat treatment before spheroidizing annealing.

\begin{tabular}{ccc}
\hline Diameter, mm & $\begin{array}{c}\text { Preliminary Heat Treatment after } \\
\text { Austenitization }\end{array}$ & Microstructure \\
\hline 17 & Furnace cooling & Ferrite-pearlite \\
21 & Air quenching & Bainite \\
17 & Oil quenching & Martensite \\
21 & Furnace cooling & Ferrite-pearlite \\
17 & Air quenching & Bainite \\
21 & Oil quenching & Martensite \\
\hline
\end{tabular}




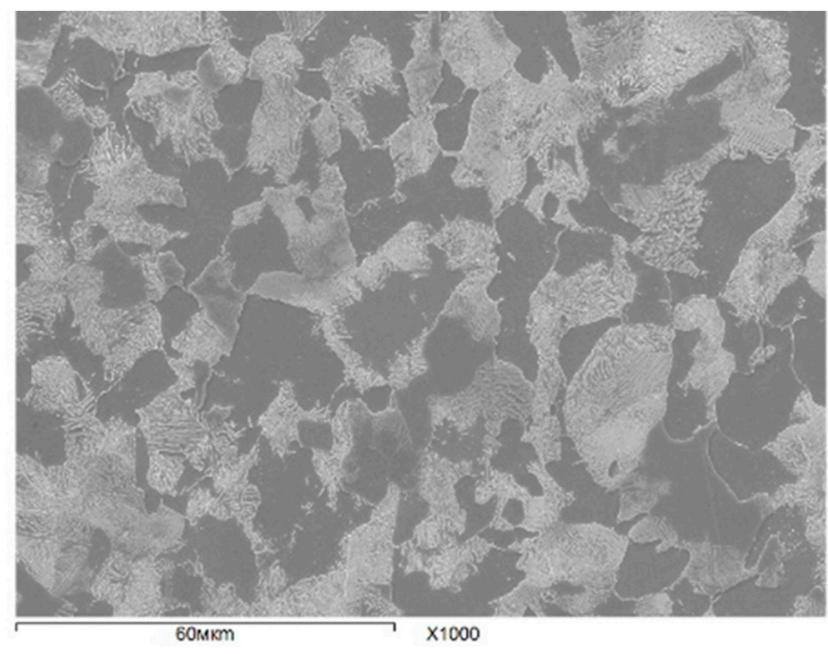

(a)

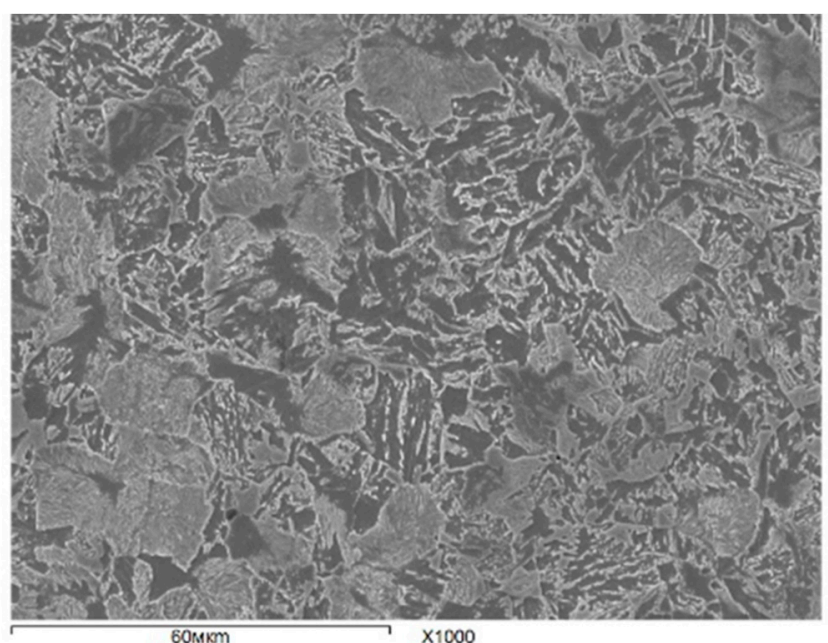

(b)

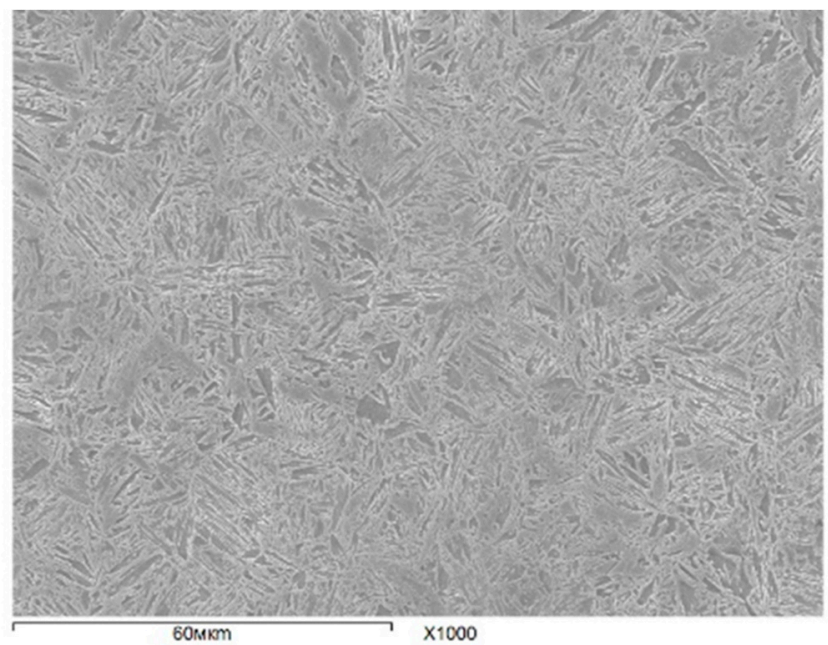

(c)

Figure 5. View of the microstructure of round bars with a diameter of $21 \mathrm{~mm}$ before spheroidizing annealing: (a) after furnace cooling; (b) after air cooling; (c) after oil quenching.

From the data in Figure 5 and Table 7 , it can be seen that by means of preliminary austenitization and subsequent cooling at various rates, samples of round bars with ferritepearlite, bainitic, and martensitic structures were obtained. Spheroidizing annealing of the obtained samples was carried out in the described tube furnace at a temperature of $730{ }^{\circ} \mathrm{C}$ for $4 \mathrm{~h}$. The results of studying the characteristics of their microstructure after spheroidizing annealing are presented in Table 8 and Figure 6.

Table 8. Characteristics of the microstructure of round bars with a diameter of $17 \mathrm{~mm}$ after spheroidizing annealing with various preliminary microstructure.

\begin{tabular}{ccc}
\hline $\begin{array}{c}\text { Microstructure before } \\
\text { Spheroidizing Annealing }\end{array}$ & $\begin{array}{c}\text { The Ratio of Globular and } \\
\text { Lamellar Pearlite after } \\
\text { Spheroidizing } \\
\text { Annealing, \% }\end{array}$ & $\begin{array}{c}\text { The Ratio of Perlite and } \\
\text { Ferrite, } \%\end{array}$ \\
\hline Ferrite-pearlite & $85 / 15$ & $75 / 25$ \\
Bainite & $95 / 5$ & $100 / 0$ \\
Martensite & $100 / 0$ & $100 / 0$ \\
\hline
\end{tabular}




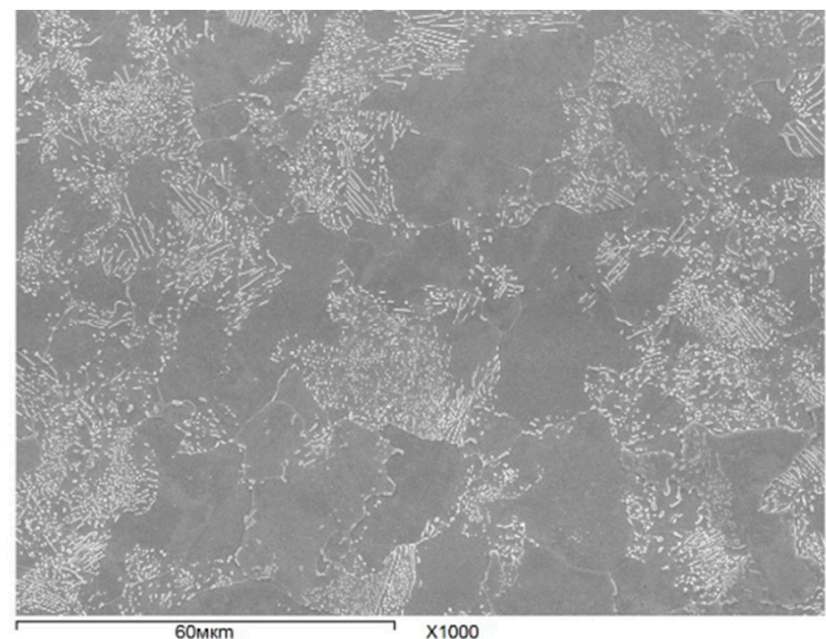

(a)

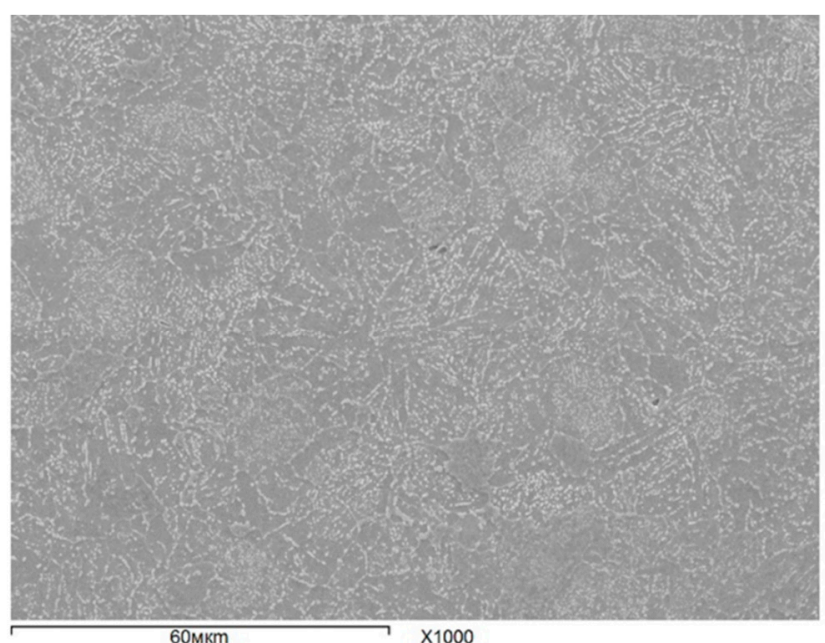

(b)

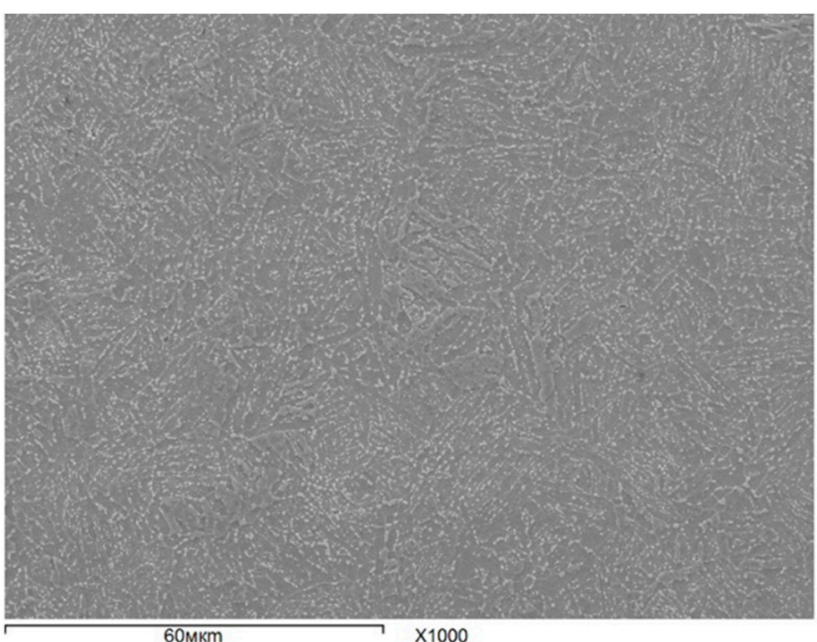

(c)

Figure 6. Microstructure of round bars after spheroidizing annealing with various preliminary microstructure: (a) ferrite-pearlite microstructure before annealing; (b) bainitic microstructure before annealing; (c) martensitic microstructure before annealing.

From the data in Table 8 and Figure 6, it follows that obtaining a bainitic or martensitic structure of bars before spheroidizing annealing makes it possible to increase the intensity of the pearlite globulization process. To determine the influence of the initial microstructure and modes of spheroidizing annealing on the mechanical properties of round bars, the mechanical properties of round bars of $21 \mathrm{~mm}$ in diameter with martensitic and bainitic structures were determined before and after annealing. The results are shown in Table 9.

Table 9. Mechanical properties of round bars with a diameter of $21 \mathrm{~mm}$ before and after spheroidizing annealing.

\begin{tabular}{cccccc}
\hline \multirow{2}{*}{$\begin{array}{c}\text { Initial } \\
\text { Microstructure }\end{array}$} & Heat Treatment & \multicolumn{4}{c}{ Mechanical Properties } \\
\cline { 3 - 6 } & & $\boldsymbol{\sigma}_{\mathbf{0 . 2}}, \mathbf{M P a}$ & $\boldsymbol{\sigma}_{\mathbf{B}}, \mathbf{M P a}$ & $\boldsymbol{\delta}, \boldsymbol{\%}$ & $\mathbf{\Psi}, \boldsymbol{\%}$ \\
\hline \multirow{2}{*}{ Bainite } & Without treatment & 480 & 710 & 15.0 & 74 \\
& Mode No. 2 & 360 & 570 & 18.5 & 71 \\
\multirow{2}{*}{ Martensite } & Without treatment & 1370 & 1920 & 5.0 & 54 \\
& Mode No. 2 & 500 & 610 & 17.0 & 75 \\
\hline
\end{tabular}


It should be noted that the values of relative reduction after spheroidizing annealing of round bars with bainitic and martensitic structures are higher than for bars with the original ferrite-pearlite structure (Table 6). However, strength characteristics of rolled products subjected to spheroidizing annealing according to mode No. 2 (Table 9) exceed the requirements of EN10263-4 ( $\sigma_{B}$ less than $550 \mathrm{MPa}$ ) for rolled products made of steel of grade $32 \mathrm{CrB} 4$.

\subsection{Assessment of Hardenability}

In order to assess the hardenability of the investigated hot-rolled bar sections, the samples with a length of $120 \mathrm{~mm}$ and a diameter of 17 and $21 \mathrm{~mm}$ were quenched in oil after austenitization at $860{ }^{\circ} \mathrm{C}$ for $1 \mathrm{~h}$. The results of microhardness measurements are shown in Figure 7.

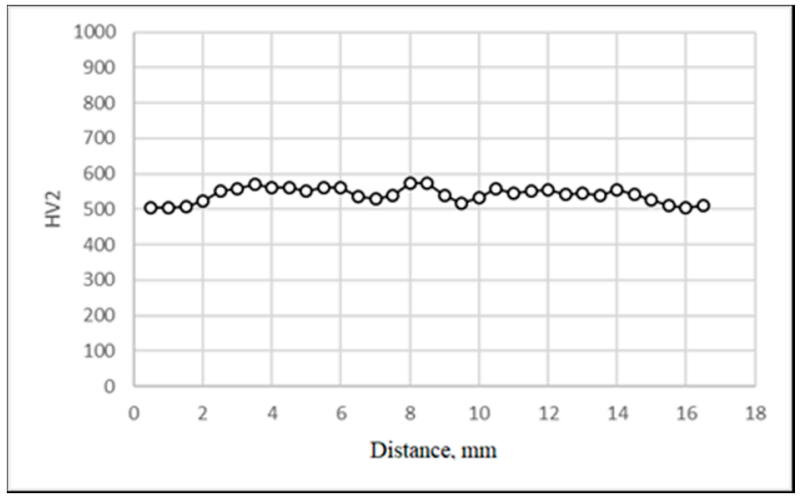

(a)

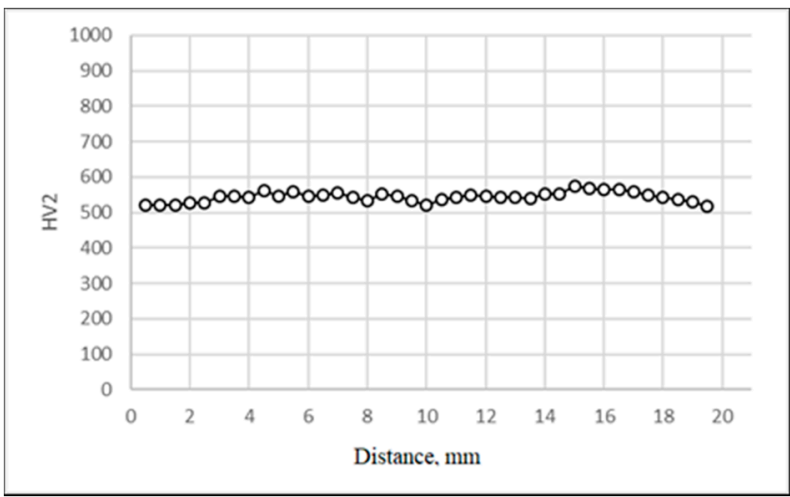

(b)

Figure 7. The results of determining the microhardness over the cross-section of round bars with a diameter of (a) $17 \mathrm{~mm}$; (b) $21 \mathrm{~mm}$.

From the data in Figure 7, it follows that during quenching in oil, the martensitic transformation of steel took place over the entire cross-section of round bars with a diameter of 17 and $21 \mathrm{~mm}$. The obtained hardness values are in the range of 48 to $50 \mathrm{HRC}$, which fully meets the requirements of EN10263-4 for steel of 32CrB4 grade (46 HRC).

To establish the effect of the austenitizing regime on hardenability, the microhardness of rolled samples with a length of $120 \mathrm{~mm}$ and diameter of $21 \mathrm{~mm}$ after holding at $900{ }^{\circ} \mathrm{C}$ for $1 \mathrm{~h}$ was investigated according to the method described above. The results are shown in Figure 8.

From the data in Figure 8, it follows that after austenitizing in this mode and oil quenching, the hardness values, which are required in accordance with EN10263-4, are achieved along the entire cross-section of the rolled product. However, in this case, a noticeable decrease in hardness occurs, and in some areas of the metal, its values meet the minimum requirements. The noted circumstance indicates a significant increase in the grain size when using this mode of austenitization of the steel under study. 


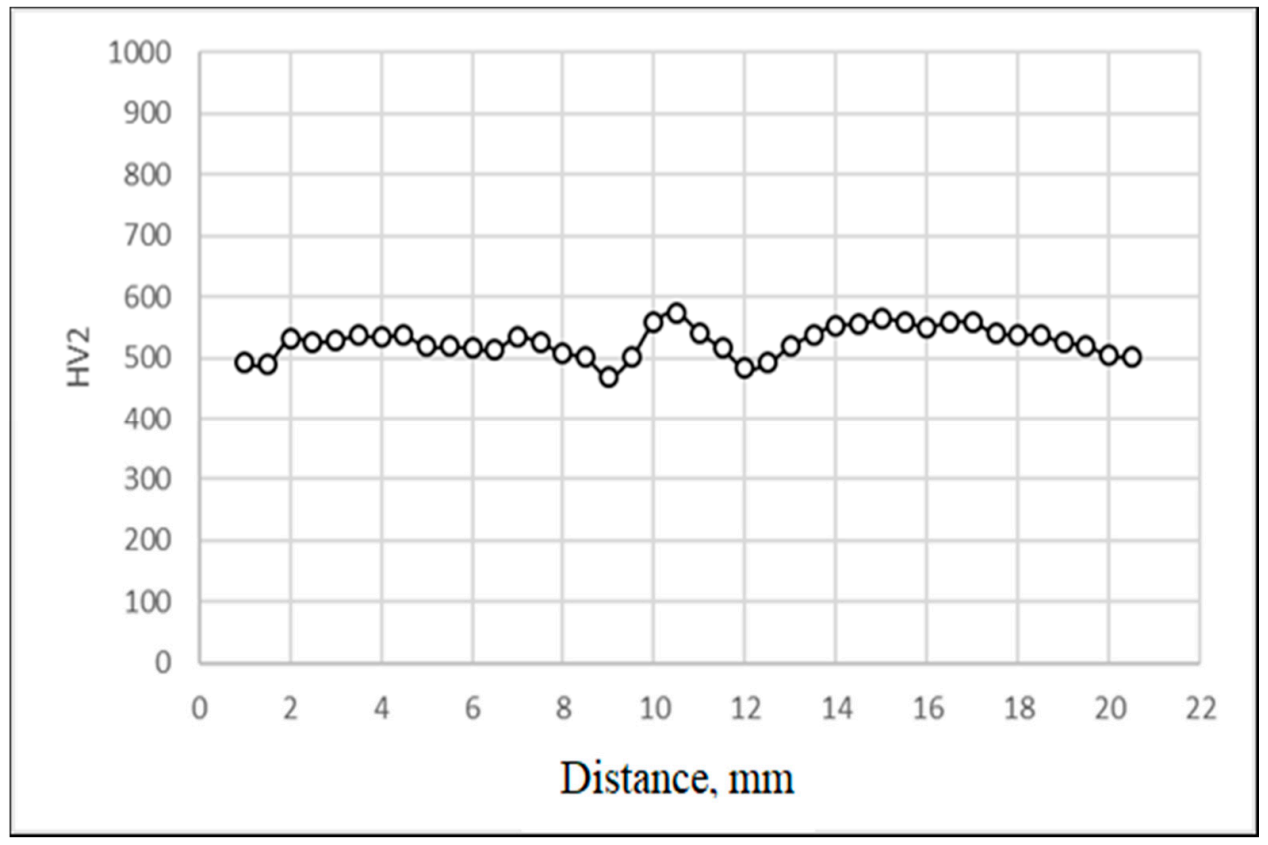

Figure 8. Microhardness over the cross-section of round bars with a diameter of $21 \mathrm{~mm}$ after austenitizing at $900{ }^{\circ} \mathrm{C}$ and oil quenching.

\subsection{Assessment of the Possibility of Manufacturing High-Strength Fasteners}

To assess the possibility of manufacturing high-strength fasteners of various strength classes from rolled steel of 32CrB4 grade, a study was made of the effect of the processes of quenching and tempering round bars on their mechanical properties. The results of the mechanical tests (Table 10) after tempering at various temperatures $\left(400-550{ }^{\circ} \mathrm{C}\right)$ showed that such a possibility exists.

Table 10. Mechanical properties of round bars after tempering in various modes.

\begin{tabular}{cccccc}
\hline \multirow{2}{*}{ Diameter, $\mathbf{m m}$} & \multirow{2}{*}{$\begin{array}{c}\text { Tempering } \\
\text { Temperatures, }{ }^{\circ} \mathbf{C}\end{array}$} & \multicolumn{3}{c}{ Mechanical Properties } \\
\cline { 3 - 5 } & 400 & 1350 & 1440 & 5.2 & 59 \\
17 & 400 & 1340 & 1440 & 5.5 & 61 \\
21 & 425 & 1280 & 1370 & 6.9 & 62 \\
17 & 425 & 1290 & 1370 & 6.3 & 61 \\
21 & 450 & 1170 & 1240 & 6.7 & 63 \\
17 & 450 & 1240 & 1280 & 6.5 & 63 \\
21 & 500 & 1030 & 1080 & 8.1 & 65 \\
17 & 500 & 1040 & 1090 & 7.9 & 63 \\
17 & 550 & 860 & 940 & 11.0 & 70 \\
21 & 550 & 830 & 910 & 11.0 & 71 \\
\hline
\end{tabular}

\section{Discussion}

The results of studying the effect of various modes of spheroidizing annealing on the microstructure of rolled $32 \mathrm{CrB} 4$ steel show that, when using temperatures above Ac1 in the two-phase region, followed by holding in the single-phase region (ferrite), it is possible to obtain a high fraction of spheroidized pearlite. At the same time, it can be assumed that there are ways to optimize the spheroidized annealing mode, in which a high fraction of spheroidized pearlite will be achieved for a shorter duration of heat treatment of the metal.

On the basis of the obtained results of studying the process of pearlite spheroidization and mechanical properties, three main zones of the studied temperatures can be distinguished: I-below Ac1 by $50-55^{\circ} \mathrm{C}$, II-below Ac1 by $10-15^{\circ} \mathrm{C}$, and III-above Ac1 by 
$5-20{ }^{\circ} \mathrm{C}$. All variants of the studied modes according to the degree of their effectiveness can be displayed graphically (Figure 9).

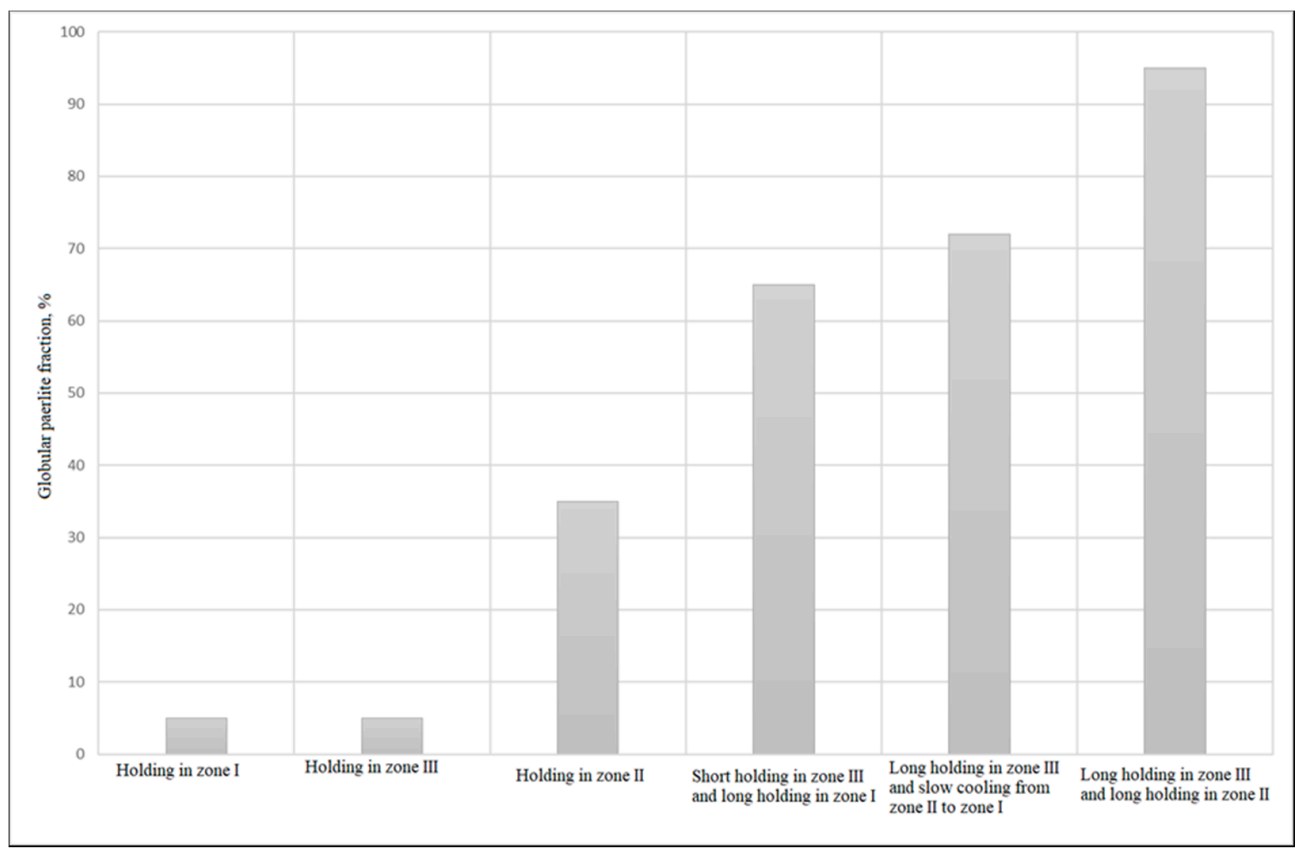

Figure 9. Average values of the globular pearlite fraction in bar sections after various modes of spheroidizing annealing.

From the data in Figure 9, it follows that annealing in regions I and III does not effectively spheroidize lamellar pearlite. Holding the metal in region II for $4 \mathrm{~h}$ makes it possible to obtain the fraction of globular pearlite up to $35 \%$. Interesting results were obtained in long and short holdings in region III, followed by slow or accelerated cooling in region I. It can be seen that even short heating of the metal to the temperature of the existence of the two-phase region can significantly accelerate the process of pearlite spheroidization. Very similar results obtained using these modes suggest that the largest fraction of globular pearlite is formed when the metal is heated to temperatures above Ac1, even for a short time. For example, when using the annealing mode No. 5 (Table 2), the rolled samples were in the temperature range III-II for about 2-3 $\mathrm{min}$, in the temperature range II-I for 7-8 $\mathrm{min}$, and in area I, the remaining time was $4 \mathrm{~h}$. The fraction of globular pearlite in the samples annealed according to mode No. 5 was $65 \%$. It is important to note that the fraction of globular pearlite obtained after annealing the samples in region I without short-term heating to temperatures above Ac1 did not exceed $5 \%$. Thus, it can be assumed that in the case of accelerated cooling after short-term holding in region III to temperatures close to Ac1 in region II, an increase in the globular pearlite fraction should follow, as evidenced by the results obtained after annealing (Table 5) according to mode No. 4. Thus, to reduce energy costs, it is advisable to study and analyze annealing modes that include a short stay of the metal in the two-phase region above Ac1 with the main holding at the temperature of ferrite stability.

An even more significant influence on the parameters of the mechanical properties of the produced high-strength fasteners is exerted by the parameters of austenitization, quenching, and subsequent tempering of steel. The results obtained show that their variation leads to a change in the strength characteristics, hardness, relative elongation, and reduction within a fairly wide range. Theoretically, it is possible to achieve the required set of values of these characteristics corresponding to all strength classes from 8.8 to 12.9 . However, an increase in strength leads to a natural decrease in the ductility (elongation) of steel. 
The results of mechanical tests after quenching and tempering of round bars indicate that there is a possibility of manufacturing fasteners of various strength classes from it in a wide range of values from 8.8 to 10.9. Since, for each strength class of fasteners in accordance with ISO 898-1, requirements are imposed on a whole range of indicators of mechanical properties in certain intervals, some values of mechanical properties were not achieved for strength classes 10.9 and 12.9. Therefore, we performed an analysis of the results obtained in order to establish the patterns of changes in mechanical properties from the tempering temperature and determine their optimal values. For this, a graphical analysis method was used.

Figure 10a shows the obtained temperature dependences of the ultimate strength and relative elongation, and Figure $10 \mathrm{~b}$ shows the hardness $\mathrm{HB}$ of round bars after quenching on the tempering temperature.

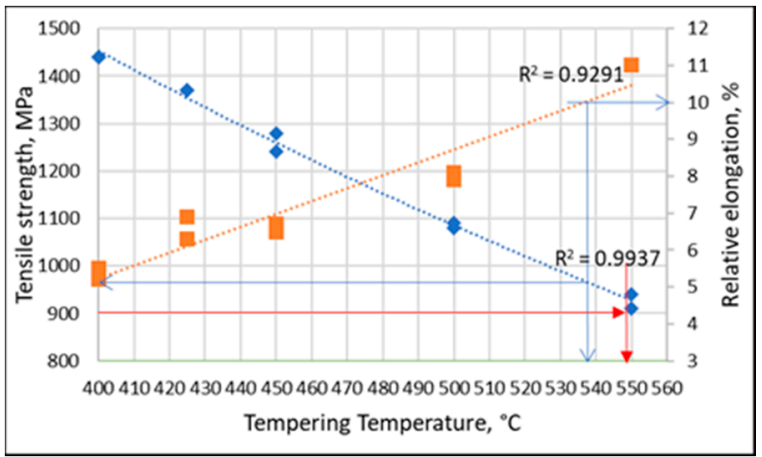

(a)

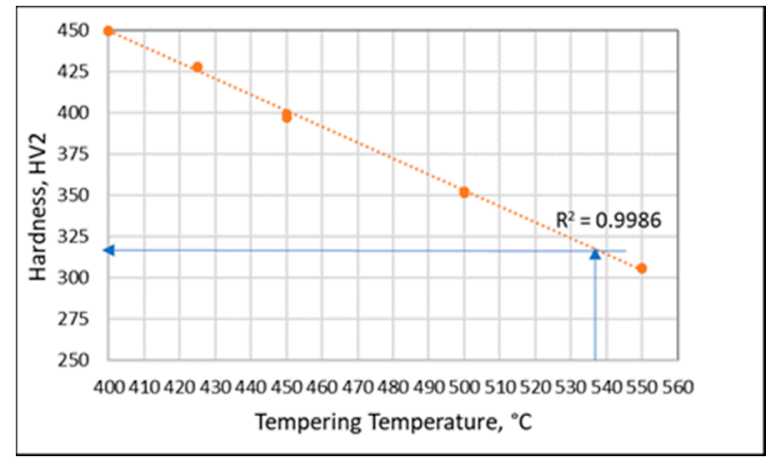

(b)

Figure 10. The established dependences of the properties of rolled products on the tempering temperature: (a) ultimate strength and elongation; (b) hardness.

Figure 10 shows that with an increase in the tempering temperature after quenching in oil, the elongation increases, and the tensile strength and hardness of bar sections decrease. Based on the requirements for high-strength fasteners according to ISO 898-1, the possibility of simultaneously achieving tensile strength indicators, relative elongation, and hardness was studied for 9.8. 10.9 and 12.9 classes. Figure 10 shows an example of the implementation of the algorithm of the graphical method for the determination of the possibility of achieving a complex of difficult-to-combine properties required for fasteners of 9.8 strength class in accordance with ISO 898-1. The indicators of relative reduction were not considered since, in the entire investigated temperature range, this characteristic of bar sections met the required values for all considered strength classes. According to ISO 898-1, the minimum elongation for fasteners with a 9.8 strength class is $10 \%$. In accordance with this, the tempering temperature $\left(537 \pm 2{ }^{\circ} \mathrm{C}\right)$ was found in Figure $10 \mathrm{a}$, at which the minimum relative elongation value required for fasteners of 9.8 strength class is reached. At this tempering temperature, the tensile strength of rolled products is $980 \pm 10 \mathrm{MPa}$ (Figure 10a). Similarly, from the data in Figure 10b, it was found that at a tempering temperature of $537 \pm 2{ }^{\circ} \mathrm{C}$, the steel has a hardness of $300 \mathrm{HB}$, which meets the requirements of $(286 \mathrm{HB}) \mathrm{ISO} 898-1$. Thus, it was found that at a tempering temperature of $537 \pm 2{ }^{\circ} \mathrm{C}$, fasteners made from rolled $32 \mathrm{CrB} 4$ steel will meet the requirements of ISO 898-1 for fasteners with a 9.8 strength class. Using a similar algorithm, we found the maximum tempering temperature of $550 \pm 2{ }^{\circ} \mathrm{C}$, at which it is possible to obtain the necessary mechanical properties for fasteners of the 9.8 strength class.

The analysis of the possibility of manufacturing fasteners of 10.9 and 12.9 strength classes from 32CrB4 steel grade was carried out in a similar way. A confirmation has been found that the complex of metal properties required for the 10.9 strength class has been achieved, but for this, it is necessary to ensure the tempering temperature in a narrow range (510-515) $\pm 2{ }^{\circ} \mathrm{C}$. According to the obtained dependencies (Figure 10), based on the results 
of studying bar sections from steel of the one chemical composition, it can be concluded that the manufacture of fasteners of the 12.9 strength class from 32CrB4steel is not possible.

Thus, it was found that an increase in the strength class of fasteners leads to a significant complication of the production technology since it requires maintaining an increasing number of parameters in narrow ranges of values. If the manufactured fasteners of the 8.8 strength class satisfied all the specified requirements with a significant margin, then in the case of the 10.9 class, there is a need to maintain the tempering temperature in a rather narrow range of values. With the guaranteed achievement of strength characteristics for fasteners of all strength classes, including 12.9, the problem arises of obtaining the required values of the relative elongation of steel. Thus, the considered steel of 32CrB4 grade, the disadvantages of which are noted above, is applicable for manufacturing fasteners of only $8.8,9.8$, and 10.9 strength classes. It should be noted that the research performed concerns batches of bar sections produced from steel of the same composition, one heat, and using only one austenitization mode. Therefore, the results obtained can serve as the basis for purposeful substantiation of the directions of subsequent research, including the development of new steels with an economical composition and optimal structural state for the effective implementation of the entire end-to-end technology for the production of round bars and the manufacture of high-strength fasteners.

\section{Conclusions}

The results of studying the characteristics of structural state elements and properties of hot-rolled round bars with diameters of 17 and $21 \mathrm{~mm}$ made of 32CrB4 steel allow a number of conclusions to be drawn. There is an insignificant depth of the decarburized layer, not exceeding $0.6 \%$ of the diameter, which indicates its predominant occurrence during the hot-rolling of steel. The main types of nonmetallic inclusions present are calcium-aluminatebased oxide inclusions, aluminum-magnesium spinel, as well as titanium nitride. Tests of bar sections after spheroidizing annealing for cold upsetting at $1 / 3$ of the initial height of the cylindrical specimen showed a positive result. Consequently, the presence of nonmetallic inclusions in the investigated rolled products does not lead to a significant decrease in its quality characteristics.

The possibility of obtaining the necessary spheroidized ferrite-pearlite structure and, as a result, the level of mechanical properties of round bars made of $32 \mathrm{CrB} 4$ steel, has been established. The optimal modes are spheroidizing annealing at $730^{\circ} \mathrm{C}(4 \mathrm{~h})$ or cooling from $760^{\circ} \mathrm{C}$ to $690^{\circ} \mathrm{C}$ for $4 \mathrm{~h}$. Obtaining a bainitic or martensitic structure of bar sections after hot-rolling of steel accelerates the process of pearlite spheroidization. Nevertheless, the process of pearlite spheroidization in $32 \mathrm{CrB} 4$ steel is difficult due to the formation of a significant fraction of ferrite in the structure during hot-rolling.

The steel of the $32 \mathrm{CrB} 4$ grade has a sufficiently high hardenability, which provides a completely martensitic structure over the entire cross-section of round bars with a diameter of 17 and $21 \mathrm{~mm}$. The obtained hardness values are in the range from 48 to $50 \mathrm{HRC}$, which fully meets the requirements of EN10263-4 (46 HRC).

Austenitization at a temperature of $860^{\circ} \mathrm{C}$ for $1 \mathrm{~h}$ for bar sections with a diameter of 17 and $21 \mathrm{~mm}$ made of from 32CrB4 steel followed by quenching in oil and tempering at temperatures from 400 to $550{ }^{\circ} \mathrm{C}$ only allows obtaining fasteners with strength classes of 8.8, 9.8, and 10.9. An increase in the strength class of fasteners leads to a significant complication of the production technology since it requires the maintenance of an increasing number of parameters in narrow ranges of values. If the manufactured fasteners of the 8.8 strength class satisfied all the specified requirements with a significant margin, then in the case of the 10.9 class, there is a need to maintain the tempering temperature in a rather narrow range of values. With the guaranteed achievement of strength characteristics for fasteners of all strength classes, including 12.9, the problem arises of obtaining the required values of the relative elongation of steel. 


\begin{abstract}
Author Contributions: Conceptualization, A.S. and A.K.; methodology, A.S.; software, A.K.; formal analysis, N.A.; investigation, A.S. and A.K.; writing-original draft preparation, N.A.; writingreview and editing, A.Z.; project administration, A.Z.; funding acquisition, A.Z. All authors have read and agreed to the published version of the manuscript.

Funding: This research was funded under Contract No. MK 212117/15-FHO-21-2-4890/B dated 1 December 2020, performed under an agreement between MMK-METIZ OJSC and the Ministry of Industry and Trade of the Russian Federation No. 020-11-2020-1988 dated 26 December 2020, state contract identifier No. 0000000002020 PWF0002.
\end{abstract}

Institutional Review Board Statement: Not applicable.

Informed Consent Statement: Not applicable.

Data Availability Statement: Not applicable.

Conflicts of Interest: The authors declare no conflict of interest.

\title{
References
}

1. Pachurin, G.V.; Fillipov, A.A.; Mukhina, M.V. Rolled stock structure preparation for cold forging of pearlite steel grades. IOP Conf. Ser. Mater. Sci. Eng. 2020, 969, 012010. [CrossRef]

2. Filipov, A.A.; Pachurin, G.V.; Goncharova, D.A.; Nuzhdina, T.V.; Mukhina, M.V.; Katkova, O.V.; Matveev, U.I.; Tsapina, T.N. Structural and mechanical maintenance of quality of the rolled stock for cold upsetting of metal articles. IOP Conf. Ser. Mater. Sci. Eng. 2019, 632, 012010. [CrossRef]

3. Stepanov, A.B.; Arutyunyan, N.A.; Ivin, Y.I.; Zaitsev, A.I. Effect of microstructure and surface defects on the capacity of special alloy steel round bar for cold upsetting. Metallurgist 2016, 60, 713-720. [CrossRef]

4. Pang, X.P.; Hu, Y.; Tang, S.L.; Xiang, Z.; Wu, G.; Xu, T.; Wang, X.Q. Physical properties of high-strength bolt materials at elevated temperatures. Results Phys. 2019, 13, 102156. [CrossRef]

5. Bobylev, M.V.; Koroleva, E.G.; Shtannikov, P.A. Promising sparingly alloyed boron-bearing steels for the production of highstrength fasteners. Met. Sci. Heat Treat. 2005, 47, 210-214. [CrossRef]

6. Xiao, Z.; Liu, H.; Liu, B.; Sun, H.; Liu, D.; Liu, G. The effect of forming parameter on multi-stage cold forging with $20 \mathrm{MnTiB}$ steel. Int. J. Adv. Manuf. Technol. 2016, 83, 1189-1197. [CrossRef]

7. O'Brien, J.M.; Hosford, W.F. Spheroidization cycles for medium carbon steels. Metall. Mater. Trans. A 2002, 33, 1255-1261. [CrossRef]

8. Fu, Y.; Yu, H.; Tao, P. On-line spheroidization process of medium-carbon low-alloyed cold heading steel. Int. J. Miner. Metall. Mater. 2014, 21, 26. [CrossRef]

9. Lundberg, S.E. A vision of wire rod rolling technology for the twenty first century. Adv. Mater. Res. 2007, 23, 39-44. [CrossRef]

10. Jirkova, H.; Hauserova, D.; Kueerova, L.; Masek, B. Energy-and-time-saving low-temperature thermomechanical treatment of low-carbon plain steel. Mater. Technol. 2013, 47, 335-339.

11. Arruabarrena, J.; López, B.; Rodriguez-Ibabe, J.M. Influence of prior warm deformation on cementite spheroidization process in a low-alloy medium carbon steel. Metall. Mater. Trans. A 2014, 45, 1470-1484. [CrossRef]

12. Dolzhenkov, I.E. Carbide morphology in steel subjected to cold deformation. Steel Transl. 2011, 41, 965. [CrossRef]

13. Gul', Y.P.; Sobolenko, M.A.; Ivchenko, A.V. Improvement in the spheroidizing annealing of low-carbon steel for cold upsetting. Steel Transl. 2012, 42, 531-535. [CrossRef]

14. Karadeniz, E. Influence of different initial microstructure on the process of spheroidization in cold forging. Mater. Des. 2008, 29, 251-256. [CrossRef]

15. Koldaev, A.V.; Amezhnov, A.V.; Zaitsev, A.I.; Stepanov, A.B. Effect of temperature-deformation treatment regime for special alloy steels on rolled product structural state and properties. Metallurgist 2018, 61, 858-862. [CrossRef]

16. Wang, B.; Liu, Z.; Zhou, X.; Wang, G. Improvement of hole-expansion property for medium carbon steels by ultra fast cooling after hot strip rolling. J. Iron Steel Res. Int. 2013, 20, 25-32. [CrossRef]

17. Saha, A.; Mondal, D.K.; Maity, J. An alternate approach to accelerated spheroidization in steel by cyclic annealing. J. Mater. Eng. Perform. 2011, 20, 114-119. [CrossRef]

18. Maity, J.; Saha, A.; Mondal, D.K.; Biswas, K. Mechanism of accelerated spheroidization of steel during cyclic heat treatment around the upper critical temperature. Philos. Mag. Lett. 2013, 93, 231-237. [CrossRef]

19. Ji, C.; Wang, L.; Zhu, M. Effect of subcritical annealing temperature on microstructure and mechanical properties of SCM435 steel. J. Iron Steel Res. Int. 2015, 22, 1031-1036. [CrossRef]

20. Shaposhnikov, N.G.; Rodionova, I.A.; Pavlov, A.A. Thermodynamic development of austenite-martensite class corrosion-resistant steels intended for a bimetal cladding layer. Metallurgist 2016, 59, 1195-1200. [CrossRef] 